SUS-RURI: Proceedings of a Workshop on Developing a Convergence Sustainable Urban Systems Agenda for Redesigning the Urban-Rural Interface along the Mississippi River Watershed held in Ames, lowa, August 12-13, 2019

\title{
Considering Air Quality and Climate Co-Benefits During Climate Mitigation and Adaptation in the Mississippi River Watershed
}

Charles Stanier

Published on: Dec 24, 2019

DOI: $10.31274 / 3 d 9 e a 6 a 4 . f b 703 f e 5$

License: Creative Commons Attribution 4.0 International License (CC-BY 4.0). 
At the workshop "Developing a Convergence SUS Agenda for Redesigning the UrbanRural Interface along the Mississippi River Watershed," five sustainability goals were repeatedly mentioned as major challenges that could be organizing themes for convergence research going forward. These included:

1. resilience against flooding, including river basin, coastal, and flash flooding;

2. management of water quality, including agricultural, suburban, and urban runoff;

3. adaptation to achieve resilience against a broad range of related climate and landuse change impacts in addition to flooding (i.e., drought, heat waves, heat stress, and power outages);

4. maintenance of vibrant rural communities; and

5. achievement of substantially lower greenhouse gas footprints necessary to mitigate the most severe effects of climate change.

A cross-cutting theme that ran through the workshop due to its focus on convergence research can be summarized as follows:

achieve knowledge co-creation in sustained feedback loops through convergence research that breaks down silos between academic disciplines, is inclusive of groups beyond traditional academic communities, and is especially inclusive of marginalized communities at risk from climate impacts.

I argue that air quality is extremely relevant to all five of the potential focus areas for sustainability convergence research concerning the Mississippi River Watershed. Air quality is relevant in two distinct ways:

1. air quality is a success story that can serve as an inspiration and template for research, policy and action on the more recalcitrant issues listed above such as flooding, greenhouse gas footprints, and water quality; and

2. air quality is tied as a co-benefit to all five of the problems listed above.

First, I show my evidence for improvement of the air quality in the Mississippi watershed. Figure 1 shows estimates of fine particulate matter, or $\mathrm{PM}_{2.5}$ (particles smaller than 2.5 microns in diameter), the most serious air pollutant in the central U.S., derived from van Donkelaar et al.[1] The left panel is for the year 2007 while the right is for 2016 .

Particles smaller than 2.5 microns are small enough to travel to and then deposit in the deep lung. They contribute to myriad health problems, including heart disease; 
arteriosclerosis; exacerbation of lung diseases such as pneumonia, emphysema, and COPD; reduction in childhood lung capacity; asthma and heart attacks; negative pregnancy outcomes; risk factors for diabetes and neurodegenerative diseases such as Alzheimer's. Evidence for a role of fine particulate matter in these health problems is robust, showing up in analysis of death rates, blood and lung chemistry, hospitalization rates, medication usage rates, and workplace and school absenteeism rates. In addition to direct medical costs, loss of life, and disability effects, air pollution also has negative effects on the economy through reduced worker productivity.

Although no safe threshold for fine particulate matter has been identified, target levels are an annual average concentration of 12 or 10 micrograms per cubic meter of air, per the US EPA and the World Health Organization, respectively. Thus, locations with colors at the yellow and higher levels are problematic. One can see the massive improvement in air quality throughout the region, with elimination of all instances of air quality worse than 12 micrograms per cubic meter by 2016, and only small areas now in the 10-12 range.

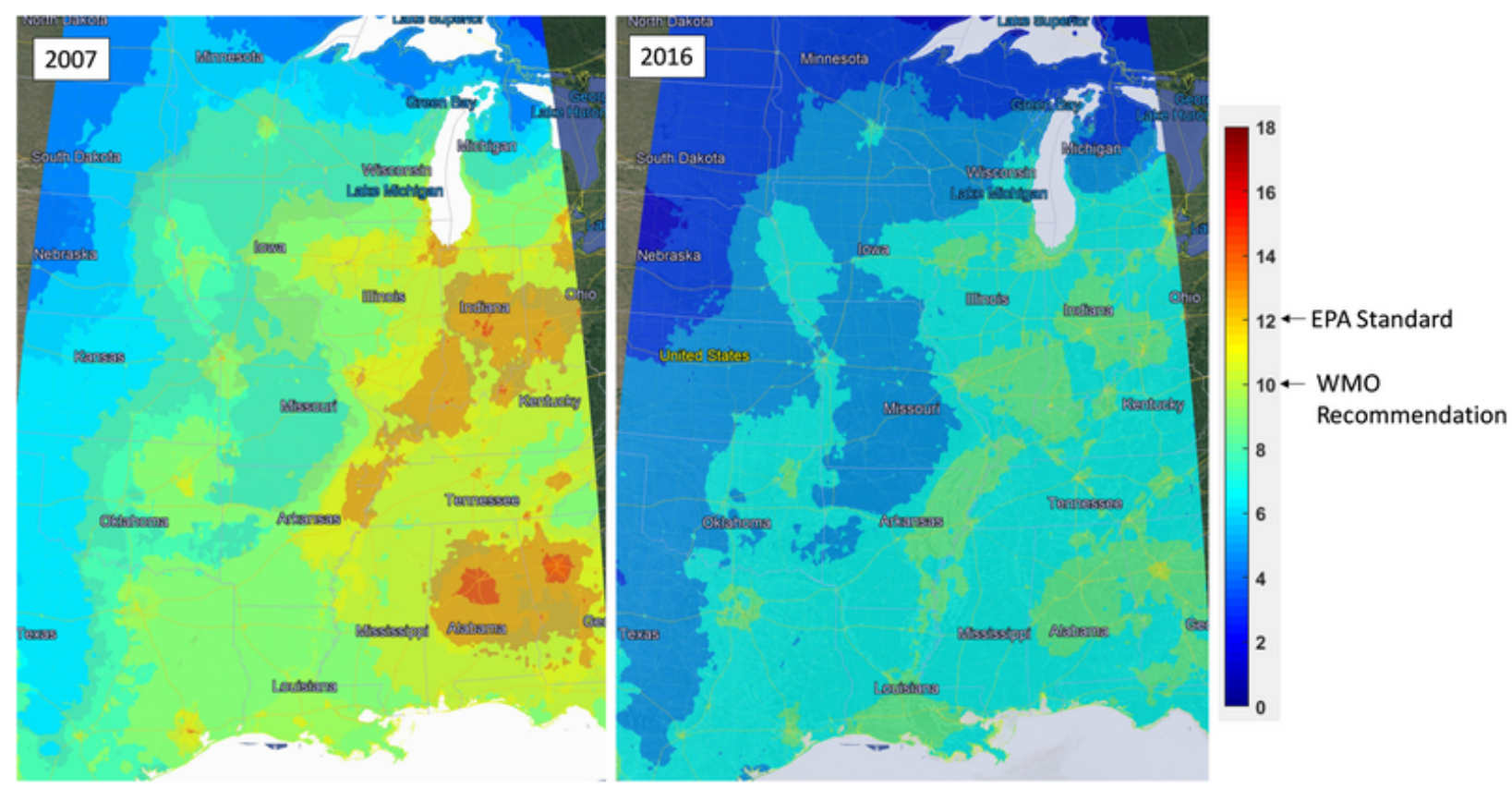

Figure 1. Map of estimated fine particle pollution $\left(\mu \mathrm{g} \mathrm{m}^{-3} \mathrm{PM}_{2.5}\right.$ ) for 2007 and for 2016. Derived from van Donkelaar et al. (2019).

In addition to a reduction in levels, there has been a "flattening" of the concentration surface in the recent decade. Figure 2 shows the improvement in air quality (fine particulate matter, using the same source as in Figure 1 [1]), that can be achieved by moving to the cleanest location within $60 \mathrm{~km}$. In 2007, and prior to 2007, centers of 
major metropolitan areas were associated with high pollution from vehicle congestion and from factory and powerplant emissions. In 2007 (red and purple) the average improvement one could achieve by moving to the cleanest location in 2007 was a decrease of 2.05 micrograms per cubic meter. There were many locations where an improvement of 3-5 could be achieved by moving, and some where the most polluted locations (usually industrial and city center locations) were 5-7 micrograms per cubic meter dirtier than some outlying suburbs. As pollution sources upgraded their pollution controls, changed fuels, and/or ceased operation, these spatial disparities in air pollution have decreased. Now in 2016 (purple and blue) the average improvement one can achieve by moving is 1.66 micrograms per cubic meter (versus 2.05 in 2007) and instances of a spatial disparity of greater than 3 micrograms per cubic meter are much rarer than they were in 2007. One downside of this is that now that city centers of major metropolitan areas are cleaner, on both a relative and absolute basis, housing costs are sometimes inflated due to high-income developments. These trends are anticipated to continue as transport and energy sectors continue to become electrified and/or low emission.

I believe this is an interesting fact for the planners that attended the workshop. This has environmental justice consequences, effects future development, and can be analyzed at the city-by-city scale for a variety of air pollutants. 


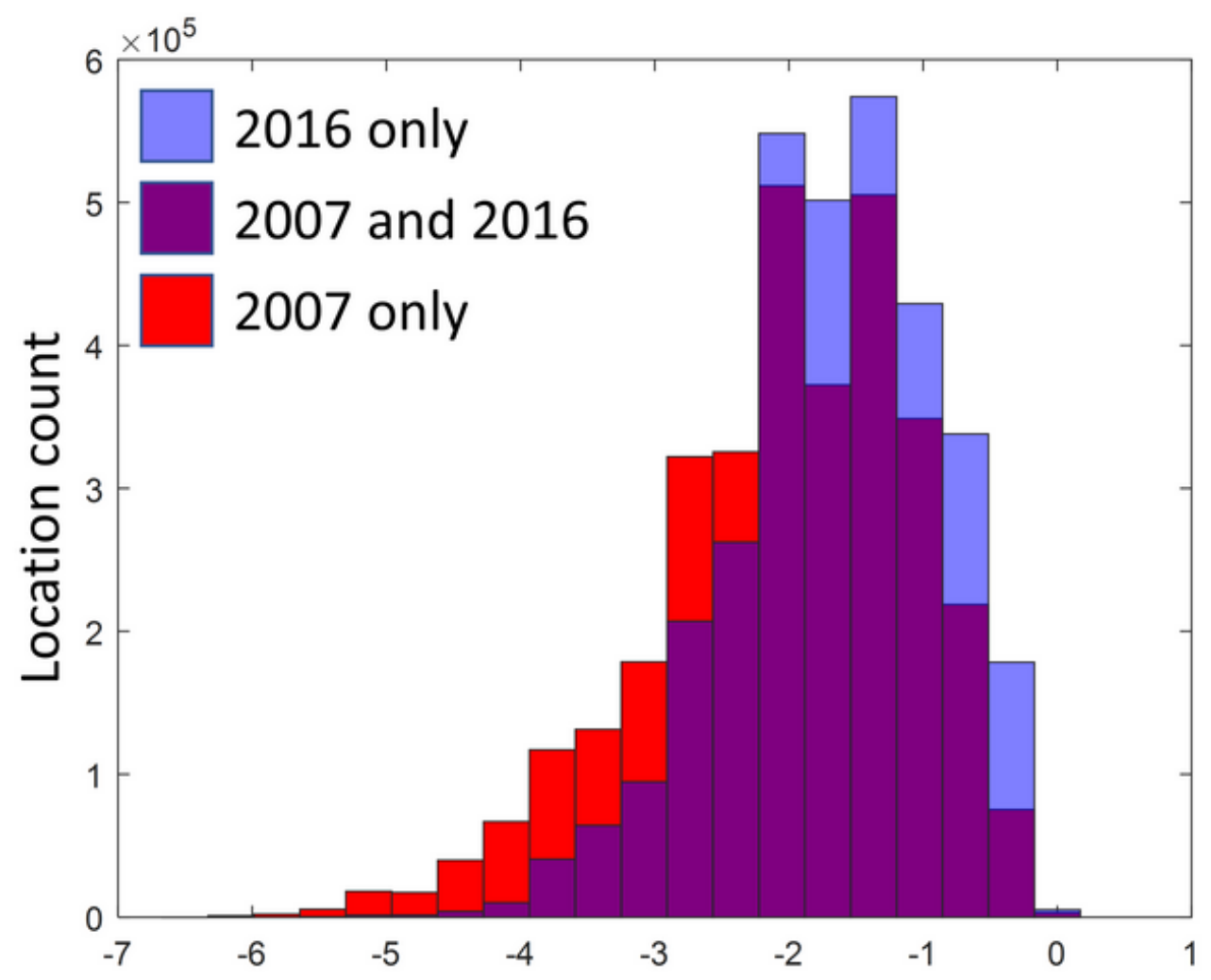

\section{Max decrease in pollution achievable by moving up to $60 \mathrm{~km}$ ( $\mu \mathrm{g} \mathrm{m}^{-3}$ fine particles as $\mathrm{PM}_{2.5}$ )}

Figure 2: Maximum difference in the annual average fine particulate pollution between a location and the cleanest location within $60 \mathrm{~km}$. Red and purple show

the distribution of this variable for 2007, and purple and blue show the distribution of this variable in 2016.

While large progress has been made regionally for air quality challenges, very large policy initiatives, market changes, and investments are required to make progress on what I refer to as the "recalcitrant" issues that were the focus of the workshop: flood resilience, water quality management including nitrogen runoff, resilience of other climate-change impacts, maintenance of vibrant rural communities, and reduction of greenhouse gas footprints.

Because of the scale of each of these problems, and their solutions, there is pressure to try to find solutions and policies that can address multiple issues at once, or at least that do not solve one problem while exacerbating another.

I illustrate the massive size of the investments required by using the greenhouse gas footprint and flood recovery spending in this section. 
Iowa's energy infrastructure and climate-sensitive built environment have considerable capital and operational costs, totaling over $\$ 28$ billion annually. These include electricity and gas systems, transportation and water infrastructure, and other construction of public and private buildings and infrastructure. Each of these three categories consumes 2-5\% of GDP per year. Even larger than those categories are capital and operating outlays for vehicles (11\% of GDP/yr). These interlinked components of the economy consume much of our economic resources, and our creative and professional effort in the planning, policy, design, engineering, and construction sectors.

Climate change mitigation (reducing emissions) and climate change adaptation (building to accommodate future climate) will require shifting some current investments within these economic sectors as well as increasing investments due to costlier alternatives and stranded assets.[2] In other words, designs will need to shift to low-carbon and resilient alternatives.

Scaling the national and international statistics listed above to Iowa and to Iowa City is instructive; it shows the massive scale of the investments that we are talking about when we consider optimizing infrastructure investments for mitigation and adaptation. In the energy sector alone, a credible climate change response (i.e., avoiding dangerous levels of climate change) is thought to require approximately $\$ 3 \mathrm{~B} / \mathrm{yr}$ (combined shifting of technologies, and increased investment) at the state level, or \$0.3B per year for the Iowa City metro area. Replicated across the other relevant economic sectors, the combined complexity, number, and value of the infrastructure decisions is overwhelming. Low-carbon resiliency across all sectors may require shifts and increases in combined public and private investment, relative to "business-asusual" baseline scenarios, exceeding $\$ 10 B / y r$ at the state level, and $\$ 1 B / y r$ in the Iowa City area.

These dollar amounts dwarf scales that academics think of in terms of grants and incentive programs. But they are the magnitude required for a response that would achieve large-scale mitigation and resiliency. The order of magnitude of these investment flows is comparable to actual investments in wind energy $\$$ \$0.6B per year in Iowa, 20-yr avg.) and to flood-related damage costs in the state. For example, 2019 flood damage is \$1.6B and counting (Lynch 2019); 30-yr average annual flood damages run at $\$ 0.6 \mathrm{~B}$ per year (Eller 2019). Another point of comparison is that the size of Iowa's Greenhouse Gas (GHG) emission trading market would be \$3.7B per year if priced at current European market trading levels. 
The way that we choose to address the challenges listed above (i.e., flood resilience, etc.) will determine the nature of the rural-urban interface (RURI) for decades to come. The details of how massive public and private investments in energy, transportation, agriculture, and stormwater unfold will determine the character of our cities, towns, and rural areas in the Mississippi River Watershed (MRW). On the optimistic side, the possibility for hitting multiple objectives exists-nutrient management, flood resilience, mobility, economic development, equity, public safety, resilience to drought/heat wave/power outage, climate change mitigation, and improved air quality. On the downside, cases where investment leads to forward progress on one goal and backsliding on other goals abound. For example, economic activity increased national U.S. GHG in 2018,[]] and Iowa emissions increased in 2017 (2018) (Iowa statistics for 2018 not yet available).

One of my research group's aims is to make sure resilience to weather extremes, climate change mitigation, and improved air quality factor into these ongoing public and private investments. We believe there is room for formal regulatory and informal consideration of the aforementioned climate and air quality factors. We are participating in the SUS-RURI workshop to seek a role in educating planners and designers in these issues. Furthermore, we seek long-term partners so that we can better reach a wide group of stakeholders to engage in education, dialogue, and new research to quantify co-benefits of making investments that further air quality, climate change mitigation, and extreme weather resilience. I also seek new research partners for large collaborative grants on coordinated Sustainable Urban Systems (SUS) research in the MRW. I believe that robust and ongoing discussions are an essential first step towards hitting multiple long-term objectives.

We recommend expanding existing air quality co-benefit discussions to include not just environmental regulators and public health specialists, but to include architects and planners as well. I would like to see my research group, and my colleagues with capabilities in air quality co-benefits, participate in convergence SUR-RURI research as energy, greenhouse gas, and air pollution specialists.

Our group's prior experience in this area consists of: (1) past Midwestern air quality analysis projects; (2) air quality education to government, citizen, and business stakeholders on air quality in the Dubuque area; (3) co-authorship on Iowa City's official Climate Change Action Plan and its draft Climate Change Adaptation plan; (4) serving on the USDA agricultural air quality task force; and (5) research on fate and transport of carbon and nitrogen as they cycle between air pollutants, greenhouse 
gases, and water pollutants. See https://www.icgov.org/project/iowa-city-climate-actionand-adaptation-plan and https://www.iihr.uiowa.edu/clear4/ and http://user.engineering.uiowa.edu/ cs_projl.

Air quality operates at all three of the scales considered by the workshop. Changes to energy infrastructure, transportation, and land use change regional (and indeed continental and hemispheric) levels of air pollution that form a background or macroscale level of air pollution. This background level of air pollution is then combined with micro-scale emission sources (e.g., individual engines, fires, combustion sources, factories, etc.) to create individual exposures that determine health effects. In cases where there are many micro-scale sources together (this occurs in cities with urban sources, in rural areas with agricultural operations, and in forested and grassland areas with wildfire), this forms a meso-scale level of air pollution where each resident's exposure is highly correlated with that of other residents. Outdoor air pollution is moderated at the micro scale by HVAC systems, mobility patterns, and building operations. And finally, buildings and their occupants emit or concentrate a variety of indoor air pollutants leading to a final personal exposure that is controlled at the micro level. My analysis has focused on all three scales, and our measurement and modeling tools can be adapted to each of these three scales.

From my perspective, the urban-rural gradient occurs at the point where localized air quality impacts and greenhouse gas emission inventory transition from mainly urban in nature (vehicles and buildings) to agricultural in nature (crop, forestry, and livestock).

Because the impacts of air pollution on health and on crops are significant, there can be significant co-benefits when strategies for climate resilience and for reduction of greenhouse gas footprints are considered. The most obvious of these is reduction in direct emission of soot from combustion sources. Soot is a potent warming agent (called a short-lived climate forcing agent) and it is a potent air pollutant. A second example is that ground-level ozone is a short-lived warming agent, and an air pollutant. Many carbon-free transport solutions and HVAC electrification options will reduce ground-level ozone pollution, and thus provide a climate and air quality co-benefit. However, there are cases where pollutant decreases in center cities may cause local increases in ozone due to nonlinearities in the chemistry of ozone production and loss.

In conclusion, I note that investments to solve these major sustainability challenges in the Mississippi River Valley (flood resilience, water quality management including nitrogen runoff, resilience of other climate-change impacts, maintenance of vibrant 
rural communities, and reduction of greenhouse gas footprints) will require very large infrastructure changes and investments; these will inevitably have air quality impacts. If designed properly, they lead to air quality improvements and improvements in environmental justice. With appropriate research and consideration in policy implementation, these can have substantial co-benefits to health and agricultural productivity. We should look at the temporal and spatial changes in air pollution to extract lessons learned and suggest strategies to move forward on issues such climate change adaptation and greenhouse gas mitigation.

\section{References}

2017 Iowa Statewide Greenhouse Gas Emissions Inventory Report. Iowa DNR.

Eller, D. (2019). Flooding has slammed every Iowa county since 1988, some as many as 17 times. Des Moines Register. Des Moines, IA, Register Media.

Lynch, J. (2019). Iowa \$1.6 billion flood damage estimate 'probably low, ' Reynolds says. The Gazette. Cedar Rapids, IA, Folience.

Masson-Delmotte, V., P. Zhai, H.-O. Pörtner, D. Roberts, J. Skea, P. R. Shukla, A. Pirani, W. Moufouma-Okia, C. Péan, R. Pidcock, S. Connors, J. B. R. Matthews, Y. Chen, X. Zhou, M. I. Gomis, E. Lonnoy, T. Maycock, M. Tignor and T. Waterfield (2018). Global Warming of $1.5^{\circ} \mathrm{C}$. An IPCC Special Report on the impacts of global warming of $1.5^{\circ} \mathrm{C}$ above pre-industrial levels and related global greenhouse gas emission pathways, in the context of strengthening the global response to the threat of climate change, sustainable development, and efforts to eradicate poverty IPCC.

Rhodium Group (2019). Preliminary US Emissions Estimates for 2018.

van Donkelaar, A., R. V. Martin, C. Li and R. T. Burnett (2019). "Regional Estimates of Chemical Composition of Fine Particulate Matter Using a Combined GeoscienceStatistical Method with Information from Satellites, Models, and Monitors." Environmental Science \& Technology 53(5): 2595-2611. https://doi.org/10.1021/acs.est.8b06392.

\section{Charles Stanier}

Professor of Chemical and Biochemical Engineering

University of Iowa 
This event is supported by the National Science Foundation, Award \#1929601. Any opinions, findings, and conclusions or recommendations expressed in this material are those of the author(s) and do not necessarily reflect the views of the National Science Foundation.

\section{Citations}

1. van Donkelaar, A., Martin, R. V., Li, C., \& Burnett, R. T. (2019). Regional Estimates of Chemical Composition of Fine Particulate Matter Using a Combined GeoscienceStatistical Method with Information from Satellites, Models, and Monitors.

Environmental Science \& Technology, 53(5), 2595-2611. https://doi.org/10.1021/acs.est.8b06392

2. Masson-Delmotte, V., P. Zhai, H.-O. Pörtner, D. Roberts, J. Skea, P. R. Shukla, A. Pirani, W. Moufouma-Okia, C. Péan, R. Pidcock, S. Connors, J. B. R. Matthews, Y. Chen, X. Zhou, M. I. Gomis, E. Lonnoy, T. Maycock, M. Tignor and T. Waterfield (2018). Global Warming of $1.5^{\circ} \mathrm{C}$. An IPCC Special Report on the impacts of global warming of $1.5^{\circ} \mathrm{C}$ above pre-industrial levels and related global greenhouse gas emission pathways, in the context of strengthening the global response to the threat of climate change, sustainable development, and efforts to eradicate poverty IPCC. $\leftrightarrows$ 3. Rhodium Group (2019). Preliminary US Emissions Estimates for 2018. 